serum and lipid fractions. This study also emphasizes the importance of using an assay procedure which is as close as practicable to conditions in vivo.

\section{REFERENCES AND NOTES}

1. Blackberg, L. and Hernell, $O$.: The bile salt-stimulated lipase in human milk. Purification and characterization. Eur. J. Biochem., 116: 221 (1981).

2. Brueton, M. J., Berger, H. M., Brown, G. A., Ablitt, L., Lyngkaran, N., and Wharton, B. A.: Duodenal bile acid conjugation patterns and dietary sulphur amino acids in the newborn. Gut, 19: 95 (1978).

3. Clayton, P. T. and Muller, D. P. R.: A simplified gas-liquid chromatographic method for the estimation of non-sulphated plasma bile acids. Clin. Chim. Acta, 105: 401 (1980).

4. Downey, W. K. and Murphy, R. F.: Association of lipases with micellar and soluble casein complexes. J. Dairy Res., 37: 47 (1970).

5. Encrantz, J. C. and Sjovall, J.: On the bile acids in duodenal contents of infants and children. Clin. Chim. Acta, 4: 793 (1959).

6. Fox, P. F., Yaguchi, M., and Tarassuk, N. P.: Distribution of lipase in milk proteins. II Dissociation from K-Casein with dimethylformamide. J. Dairy Sci., 50: 307 (1967).

7. Gidez, L. I.: Effect of dietary fat on pancreatic lipase levels in the rat. J. Lipid Res., 14: 169 (1973).

8. Hall, B.: Uniformity of human milk. Am. J. Clin. Nutr., 32: 304 (1979).

9. Hall, B. and Muller, D. P. R.: Studies on the bile salt stimulated lipolytic activity of human milk using whole milk as source of both substrate and enzyme. I Nutritional implications. Pediatr. Res., 16: 251 (1982).

10. Hernell, O.: Human milk lipases. III Physiological implications of the bile saltstimulated lipase. Eur. J. Clin. Invest., 5: 267 (1975).

11. Hernell, $O$, and Olivecrona, T.: Human milk lipases. II Bile salt-stimulated lipase. Biochim. Biophys. Acta, 369: 234 (1974).

12. Hernell, $O$. and Olivecrona, $T$.: Human milk lipases. I Serum-stimulated lipase. J. Lipid Res., 15: 367 (1974).

13. Hofmann, A. F.: Thin-layer adsorption chromatography of free and conjugated bile acids on silicic acid. J. Lipid Res., 3: 127 (1964).

14. Jensen, R. G.: Lipolysis. J. Dairy Sci., 47: 210 (1964).

15. Wooding, F. B. P.: Comparative mammary fine structure. Symp. Zool. Soc. London, 41: 1 (1977).

16. We wish to thank Dr. D. Harvey (Queen Charlotte's Maternity Hospital, London W.1.) for allowing us to study the milk from women under his care, the staff of Victoria Ward for their help and cooperation and the breast feeding promotion group of The National Childbirth Trust for putting us in contact with some of the women. We would also like to thank Professors $\mathrm{O}$. H. Wolff and J. T. Harries for their helpful advice during the course of the study. BH is grateful to Farley Health Products Limited for financial support.

17. Requests for reprints should be addressed to: Dr. D. P. R. Muller, Department of Child Health, Institute of Child Health, 30 Guilford St., London, WCIN IEN, England.

18. Dr. B. Hall thanks Farley Health Products Ltd. for financial support.

19. Received for publication June $1,1982$.

20. Accepted for publication December 9, 1982.

\title{
Pulmonary Vascular Effects of Amrinone in Conscious Lambs
}

\author{
MARK C. MAMMEL, STANLEY EINZIG, THOMAS J. KULIK, THEODORE R. THOMPSON, AND \\ JAMES E. LOCK ${ }^{(21)}$ \\ Divisions of Pediatric Cardiology and Neonatology Department of Pediatrics, University of Minnesota, \\ Minneapolis, Minnesota, USA
}

\begin{abstract}
Summary
The direct pulmonary vascular effects of amrinone, a nonglycoside, noncatechole cardiotonic agent were studied in conscious newborn lambs using a double-flow probe preparation that allows separation of direct and indirect pulmonary vascular effects. Amrinone was found to be a direct pulmonary vasodilator with a threshold dose of $0.3 \mathrm{mg} / \mathrm{kg}$. Amrinone also increased cardiac output and decreased aortic pressure at somewhat higher threshold doses $(1.0 \mathrm{mg} / \mathrm{kg}$ and $3.0 \mathrm{mg} / \mathrm{kg}$, respectively). Amrinone's peak effect on pulmonary resistance appeared greater than its peak systemic effects. These effects were noted in both normoxia and hypoxia, and were not changed by pretreatment with propranolol.
\end{abstract}

The appearance of right ventricular enlargement and pulmonary arterial hypertension (cor pulmonale) is ominous when associated with chronic lung disease. The ideal therapy for cor pulmonale would be directed at the underlying lung disease, although this is seldom possible. For cardiovascular therapy to be most effective, it should provide positive inotropic effects and pulmonary vasodilitation. Traditional therapy has consisted of digitalis, diuretics, and oxygen. Although oxygen may contribute in lowering pulmonary vascular resistance, diuretics neither improve cardiac output nor dilate the pulmonary vessels. Although digitalis may improve cardiac output, it is a known pulmonary vasoconstrictor $(10,17)$ and is of questionable benefit in cor pulmonale (10).

An orally active inotropic agent capable of dilating pulmonary vessels might be particularly useful in the therapy of cor pulmonale. Amrinone, (Fig 1), a bipyridine derivative [5-amino-3,4'bipyridine-6(1H)-one], has been shown recently to be a strong positive inotrope in vitro and in vivo in both animals $(1,2,8)$ and in man $(3,6,11)$. It is active both orally $(11,19)$ and intravenously, and does not produce arrhythmias even at high doses (14); however, its pulmonary vascular effects are unknown.

In the present study, we have investigated the pulmonary vascular effects of amrinone in lambs. Amrinone is known to have effects on cardiac output $(3,14,19)$ and systemic vascular resistance (7). Because changes in these variables are known to indirectly alter calculated pulmonary resistance, $(5,9)$ the experimental design should allow separation of direct from indirect effects of a drug on the pulmonary circulation. The pulmonary vascular effects of amrinone were, therefore, studied using a double-flow probe preparation that allows determination of local pulmonary vascular responses in vivo.

\section{MATERIALS AND METHODS}

The advantages and limitations of the double-flow probe preparation that we used have been described in detail elsewhere (16). 
Blood flows are measured separately in the two lungs; the agent under investigation is injected into one pulmonary artery and local pulmonary vascular effects are determined from changes in the ratio of flow to the injected lung over the total flow $\left(\mathrm{Q}_{\mathrm{inj}} / \mathrm{Q}_{\mathrm{t}}\right)$.

Seven infant lambs of either sex, weighing $4.8-7.6 \mathrm{~kg}$, underwent surgery at 10-27 days of age. Modified C \& C Instrument flow probes were placed around the right and left pulmonary arteries after ligation and division of the nonpatent ductus arteriosus. The probes were secured by passing 3-0 polypropylene sutures through holes in their tipss thus preventing dislodgement during 1-2 wk of chronic implantation. In three animals indwelling lines were placed in the left atrium via a left atrial appendage purse string and filled with heparinized saline $(100 \mathrm{unit} / \mathrm{ml})$. The probe connectors and left atrial lines were tunneled into the subcutaneous tissue between the scapulae and the thorax, and the skin was closed. Five to nine days were allowed for full recovery (resting respirations less than $40 / \mathrm{min}$ ) and fixation of the probes in the mediastinum. Animals with roentgenologic or clinical signs of impaired pulmonary function were not investigated. Two animals were studied on two separate occasions using different pulmonary arteries. One animal (at the time of the second study) and another animal (when studied initially) had markedly diminished cardiac output ( $<100 \mathrm{ml} / \mathrm{kg}$ ); data from these studies were excluded from further analysis. A total of seven dose-response curves in six lambs were analyzed.

Four animals, three from the group of seven listed above and one additional lamb, were studied before and after treatment with propranolol $(1 \mathrm{mg} / \mathrm{kg})$; one of these animals was studied twice before and twice after treatment with propranolol $(1 \mathrm{mg} / \mathrm{kg})$ during normoxia. Five studies were performed in four animals after propranolol treatment during normoxia and four studies were performed in four propranolol-treated animals during hypoxia.
On the day of the experiment, the animals were anesthetized with ketamine $\mathrm{HCl}(10 \mathrm{mg} / \mathrm{kg}$ intravenously) and heparinized (200 unit $/ \mathrm{kg}$ ). The probe connectors were exteriorized, a catheter was placed in the aortic root, and the tip of a soft \#5 French balloon-tipped catheter was positioned just distal to either the right or left flow probe under fluoroscopic guidance. At least 75 min were allowed between anesthesia and the first test injection; however, most animals regained consciousness within $15 \mathrm{~min}$ of a ketamine dose.

During the experiments, the animals were lightly restrained, suspended sternum down in a cloth sling. The fluid-filled aortic, pulmonary, and left atrial catheters were connected to Statham P23 Db strain gauges and the right and left pulmonary blood flows were measured with Statham SP2202 flow meters. All pressure and flow signals were recorded on an Electronics for Medicine DR-12 optical recorder. Blood gases were measured with an Instrumentation Laboratory analyzer.

Experiments were performed during normoxia (animal breathing room air) and isocapneic hypoxia $\left(\mathrm{FiO}_{2}=0.12\right.$ and $\mathrm{FiCO}_{2}=$ 0.05 ). The added $\mathrm{CO}_{2}$ prevented the development of hypoxiainduced alkalemia. Animals were tested under hypoxia and normoxia on the same day, but the sequence of the test was varied. To induce hypoxia, the unsedated lamb was placed under a clear plastic hood with access ports for the catheters and flow probe connectors. The mixture of $\mathrm{N}_{2}, \mathrm{O}_{2}$, and $\mathrm{CO}_{2}$ was delivered at a total flow rate of 4-6 liter $/ \mathrm{min}$. Fifteen minutes were required for equilibration. In preliminary experiments, it was determined that an $\mathrm{FiO}_{2}$ of 0.12 , while producing substantial pulmonary vasoconstriction, caused minimal apparent discomfort to the lamb.

Amrinone (WIN 40680) was dissolved in $0.25 \mathrm{~N}$ lactic acid to a concentration of $10 \mathrm{mg} / \mathrm{ml}$. Aliquots of this solution was then diluted with sterile water to a final concentration of 0.5 to $3 \mathrm{mg}$ / $\mathrm{ml}$ (300-400 mOsm/liter). Test solutions were prepared less than

Table 1. Hemodynamic effects of amrinone ${ }^{1}$

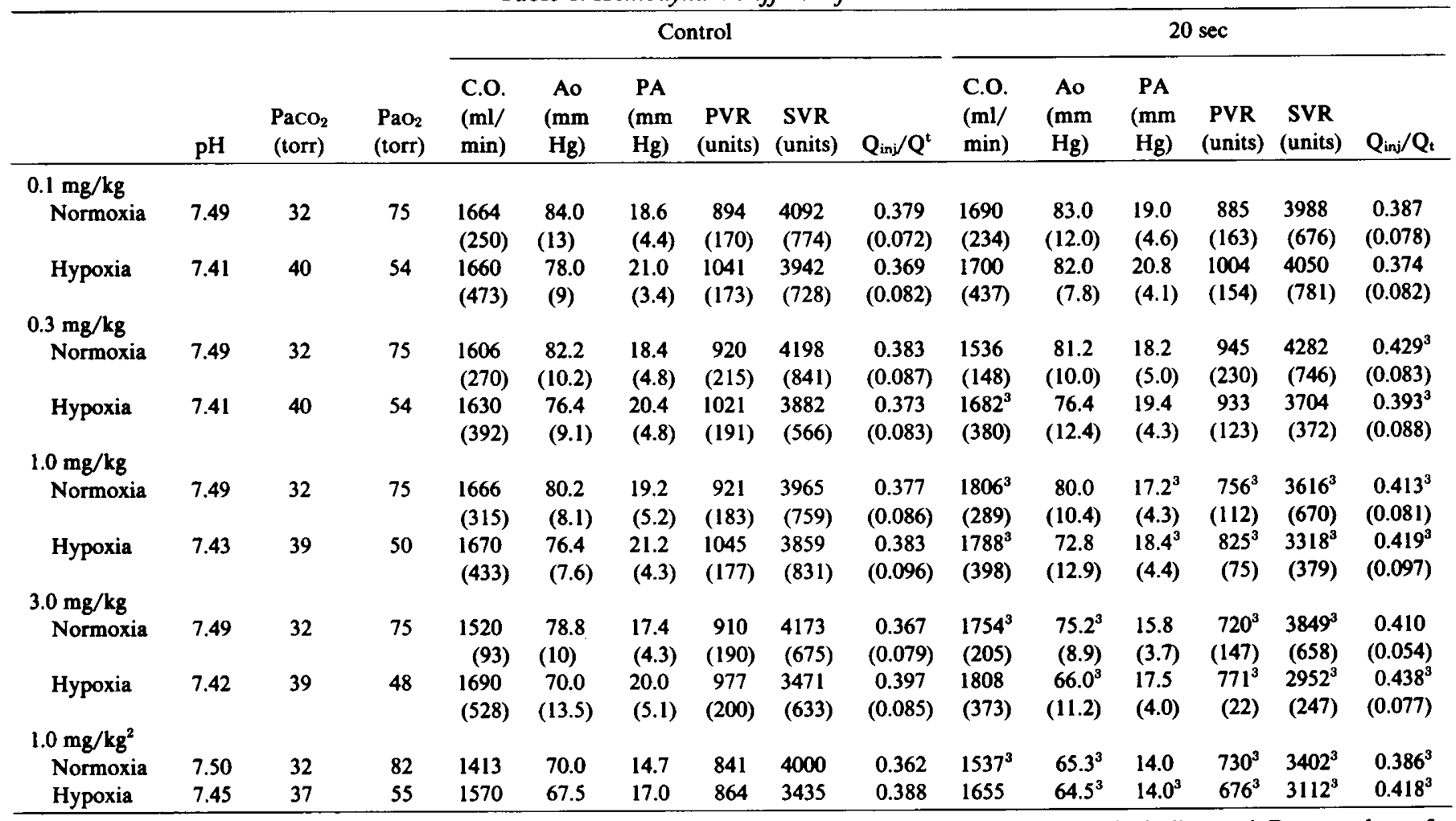

${ }^{1}$ A summary of the hemodynamic effects of amrinone. Values shown are means with standard deviations parenthetically noted. Data are shown for all amrinone doses during normoxia and hypoxia from seven experiments in six native animals; from five experiments during normoxia and four experiments during hypoxia in four propranolol-pretreated animals. Units for PVR and SVr are dynes. $\mathrm{sec} / \mathrm{cm}^{5}$. Control data and data reflecting peak drug effect (20 sec after injection) are shown. Definitions: C.O., cardiac output; Ao, aortic pressure; PA, pulmonary artery pressure, PVR, pulmonary vascular resistance; and SVR, systemic vascular resistance.

${ }^{2}$ After pretreatment with propranolol; $1 \mathrm{mg} / \mathrm{kg}, n=5$ (normoxia) and $n=4$ (hypoxia).

${ }^{3} P<0.05$ when compared to controls. 
$60 \mathrm{~min}$ before injection. Control experiments showed that the compound did not lose its activity over a $2-h$ period and that the vehicle alone had no measurable hemodynamic effects.

Compounds were injected into a branch pulmonary artery after the lamb had become quiet (hear rate $<210$ ). Injections were made by hand in $0.5-5 \mathrm{ml}$ volumes over $1-3 \mathrm{sec}$ and were flushed with a maximum of $5 \mathrm{ml}$ of lactic acid. Doses of $0.1,0.3,1.0$. and 3.0 $\mathrm{mg} / \mathrm{kg}$ were studied. Hemodynamic variables were measured at $10-, 20-, 30-, 60-$, and $120-\mathrm{sec}$ intervals after injection; the maximum effects occurred during this period for all four doses. The order of injections was varied to minimize the influence of tachyphylaxis on the dose response curves and the interval between successive injections was adjusted to allow full recovery. The study protocol was approved by the Animal Care Committee of the University of Minnesota. Differences between control and experimental findings were compared by a two-tailed paired Student's $t$ test. All results are expressed as the means \pm S.D. All differences cited in the text are significant at the $P=0.05$ level or less.

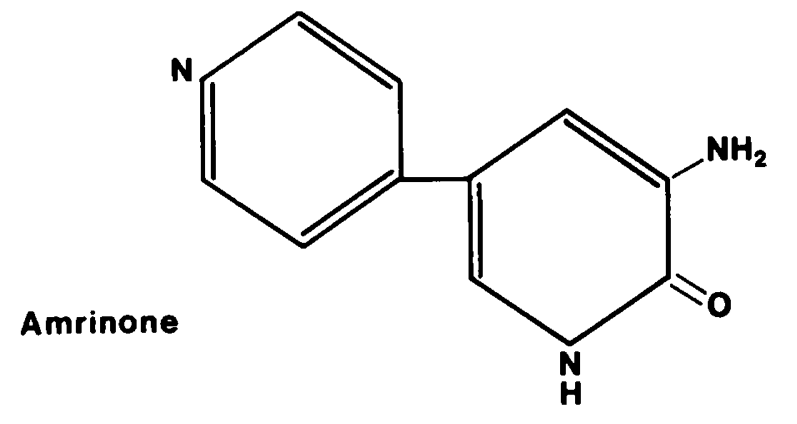

5-amino-3,4-bipyridin-6 $1 \mathrm{H}$ ) - one

Fig. 1. The chemical structure of amrinone.

\section{RESULTS}

Blood gas and $\mathrm{pH}$ status, as well as changes in cardiac output, pulmonary artery and aortic pressures, systemic and pulmonary vascular resistances, and the ratio of flow to the injected lung over total lung flow during the control period and $20 \mathrm{sec}$ (the time of peak effect) after amrinone injection are summarized in Table 1 for six lambs. Hypoxia (48-55 torr) raised baseline pulmonary artery pressure $(11-16 \%)$ without significantly altering cardiac output, aortic pressure, or systemic vascular resistance. These values were not changed by pretreatment with propranolol.

Systemic effects. Amrinone directly increased cardiac output in both normoxic and hypoxic lambs with a threshold of $1 \mathrm{mg} / \mathrm{kg}$. The change occurred without a fall in aortic pressure at $1 \mathrm{mg} / \mathrm{kg}$, suggesting a direct myocardial effect of the drug. At higher doses, aortic blood pressure fell, indicating systemic vasodilation. The increased cardiac output resulted in a fall in systemic vascular resistance at both 1 and $3 \mathrm{mg} / \mathrm{kg}$ amrinone produced no significant change in heart rate or mean left atrial pressure at or below threshold doses, and did not cause visible agitation in these conscious lambs.

Pulmonary vascular effects. The direct effects of amrinone on pulmonary vascular smooth muscle were assessed from changes in the ratio of flow to the injected lung over total pulmonary blood flow $\left(Q_{i n j} / Q_{t}\right)$. Amrinone significantly increased this ratio with a threshold dose of $0.3 \mathrm{mg} / \mathrm{kg}$ (Fig. 2). Vasodilation occurred in both normoxia and hypoxia to a similar degree. These findings indicate that amrinone directly dilates pulmonary vascular smooth muscle independently of its systemic vascular effects. This pulmonary vasodilation was not blunted by pretreatment with propranolol (Table 1).

Although amrinone would appear to directly dilate both pulmonary vascular and systemic vascular beds, it may not affect the two systems equally. The threshold for direct pulmonary vasodilation $(0.3 \mathrm{mg} / \mathrm{kg})$, as determined by a change in $Q_{\text {inj }} / Q_{t}$, is lower

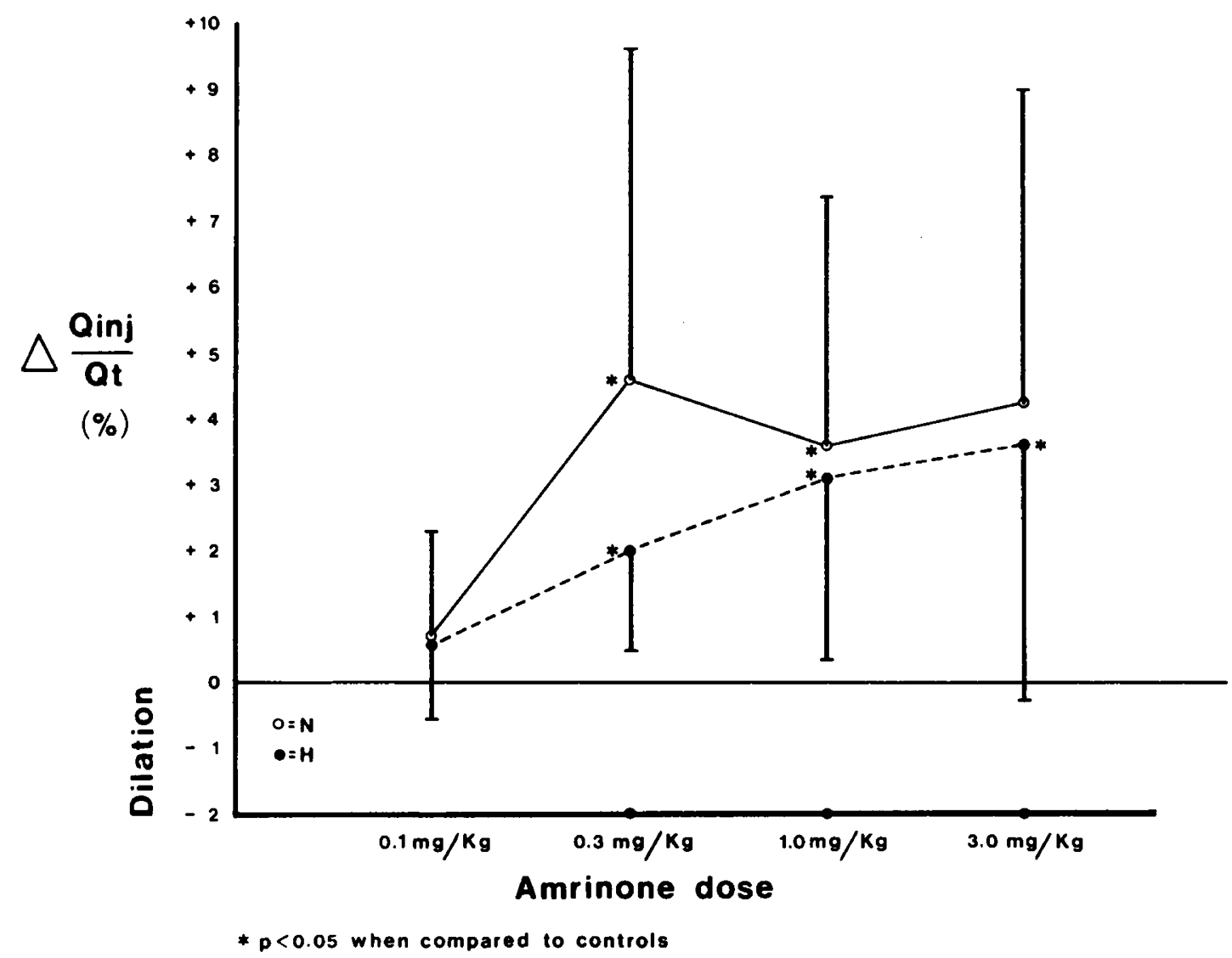

Fig. 2. Local pulmonary vasodilation induced by increasing doses of amrinone injected into a branch pulmonary artery during normoxia and hypoxia. Log dose curves are shown. Measurements were made $20 \mathrm{sec}$ after injection. 


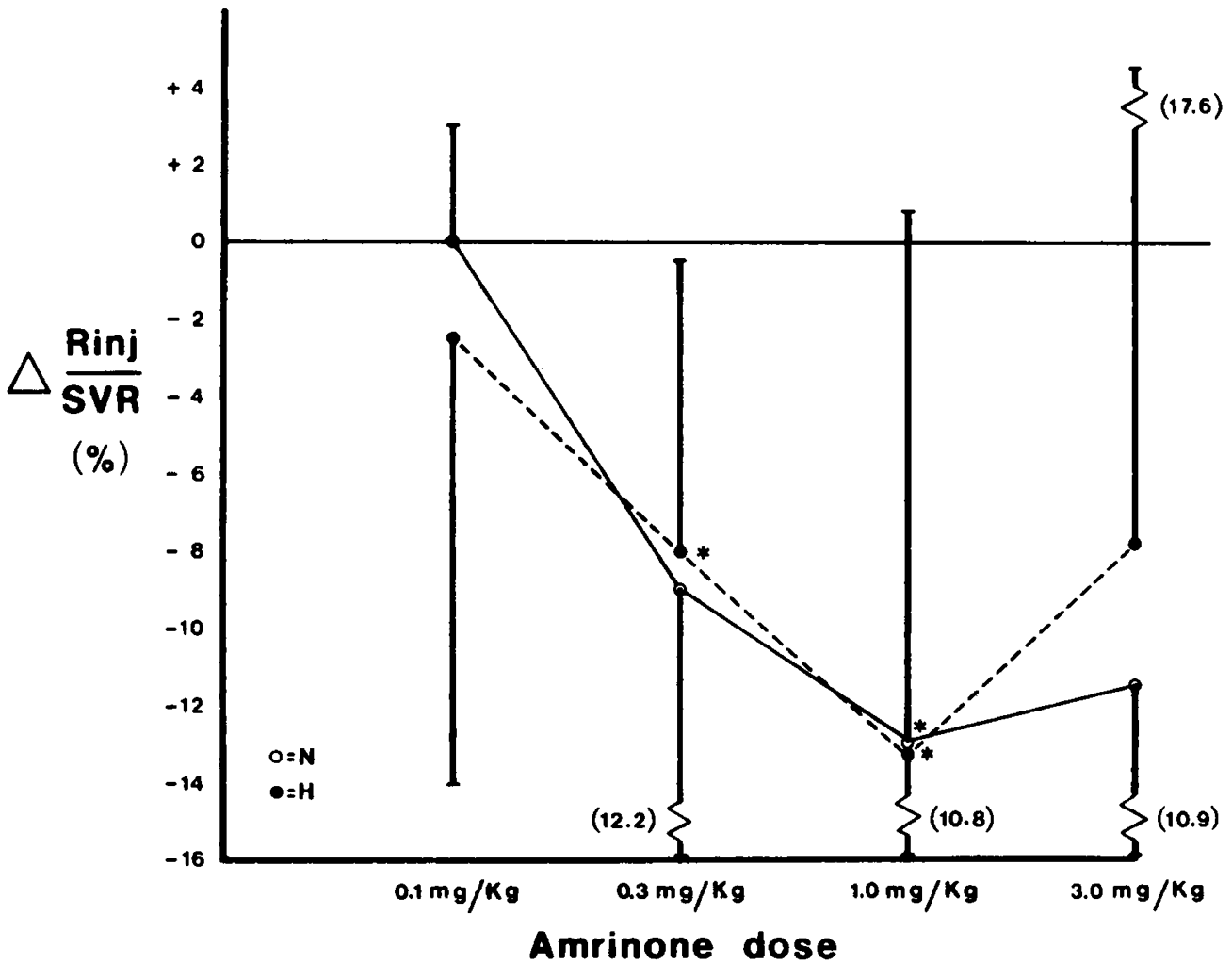

* $p<0.05$ when compared to controls

Fig. 3. The change in the ratio of resistance of the injected lung $\left(R_{\text {inj }}\right)$ to systemic vascular resistance (SVR) with increasing amrinone dose in normoxia and hypoxia measured $20 \mathrm{sec}$ after injection. Log dose curves are shown. Parenthetical notations represent standard deviations.

than the threshold for either a fall in systemic vascular resistance $(1 \mathrm{mg} / \mathrm{kg})$ or a fall in aortic blood pressure $(3 \mathrm{mg} / \mathrm{kg})$. In addition, the decrease in pulmonary resistance appears greater than the fall in systemic resistance: when the ratio of resistance in the injected lung over systemic resistance is examined (Fig. 3), the ratio fell at doses of $0.3 \mathrm{mg} / \mathrm{kg}$ and $1 \mathrm{mg} / \mathrm{kg}$. Again, these effects are not blunted by propranolol pretreatment.

\section{DISCUSSION}

Amrinone is a nonglycoside, noncatechole cardiac inotropic agent, which is currently used in the therapy of chronic congestive heart failure in adults $(3,4,12,13,14,18,19)$. Its inotropic effects have been established in isolated muscle preparations $(2,8)$, intact animals $(1,2,8)$, and in humans $(3,6,11)$. At high doses, it causes systemic vasodilation. Amrinone's augmentation of cardiac output may indirectly decrease calculated pulmonary vascular resistance; however, any direct effects of amrinone on the pulmonary circulation have not previously been documented.

In the current study, amrinone was found to be a direct pulmonary vasodilator with a threshold dose of $0.3 \mathrm{mg} / \mathrm{kg}$. This effect was not significantly influenced by alveolar hypoxia. As is true for its inotropic effects, amrinone-induced pulmonary vasodilation is not blunted by propranolol, indicating that beta-adrenergic receptors are not the mediators of its vascular effects.

Amrinone was also found to be a systemic vasodilator; however, using the threshold dose and peak drug effect as a gauge, amrinone may be a more potent pulmonary vasodilator than a systemic vasodilator in the infant lamb. Such a comparison between pulmonary and systemic vascular drug effect is clearly imperfect. For instance, changes in $Q_{\text {inj }} / Q_{t}$ may well be a more sensitive indicator of pulmonary vasodilation than changes in aortic pressure are of systemic vasodilation. Nonetheless, the notion that amrinone has some selectivity for pulmonary dilation is supported by the observation that none of a wide variety of compounds we have studied previously in this fashion have had effects similar to those of amrinone (15). Finally, the pulmonary effects of amrinone oc- curred at the same doses which have been employed in clinical trials $(3,4,6,11-14,18,19)$.

The finding that an orally active inotropic agent is also a direct pulmonary vasodilator may have particular importance in the management of cor pulmonale. The development of cor pulmonale is a final common pathway of unrelenting chronic lung disease in both children and adults. In the absence of effective treatment for the underlying lung disease, the progressive increase in right ventricular afterload results in cardiac decompensation and death. Amrinone, a positive inotrope with direct pulmonary vasodilator effects, may be useful in ameliorating this condition. It may also be of benefit in other clinical situations characterized by increased pulmonary vascular resistance and compromised cardiac output. In the absence of any agent known to be effective in cor pulmonale, clinical trials of amrinone in pediatrics may be warranted.

\section{REFERENCES AND NOTES}

1. Alousi, A. A., Farah, A. E., Lesher, G. Y., and Opalka, C. J. Jr.: Cardiotonic activity of amrinone-Win 40680 [5-amino-3,4'-bypyridin-6(IH)-one]. Fed. Proc. (Abstract), 37: 914 (1978).

2. Alousi, A. A., Farah, A. E., Lesher, G. Y. and Opalke, C. J. Jr.: Cardiotonic activity of a amrinone-Win 40680 [5-amino-3,4'-bypyridin-6(1H)-one]. Circ. Res., 45: 666 (1979).

3. Benotti, J. R., Grossman, W., Braunwald, E., Davolos, D. D., and Alousi, A. A. Hemodynamic assessment of amrinone: a new inotropic agent. N. Engl. J. Med., 299: 1373 (1978).

4. Benotti, J. R., Grossman, W., Braunwald, E., and Carabello, B. A.: Effects of amrinone on myocardial energy metabolism and hemodynamics in patients with severe congestive heart failure due to coronary artery disease. Circulation, 62: 28 (1980).

5. Daly, I deB, and Daly, M. deB.: The effects of stimulation of the carotid sinus baroreceptors on the pulmonary vascular bed in the dog. J. Physiol. (London), 148: 220 (1959).

6. de Guzman, N. P., Munoz, O., Palmer, R. F., Davolos, D. D., and Alousi, A. A.: Clinical evaluation of amrinone (a)-a new inotropic agent. Circulation, 58: 183 (1978).

7. Einzig, S., Rao, G. H. R., Pierpont, M. E., and White, J. G.: Acute effects of amrinone on regional myocardial and systemic blood flow distribution in the dog. Can. J. Physiol. Pharmacol., 60: 811 (1982).

8. Farah, A. E. and Alousi, A. A.: New cardiotonic agents: a search for digitalis substitute. Life Sci., 22: 1139 (1978). 
9. Fishman, A. P.: Dynamics of the pulmonary circulation. In: W. F. Hamilton and P. Dow, (Eds.): Handbook of physiology, Vol. Il, Section 7.: Circulation. pp. 1696-1699 (American Physiological Society, Washington, D. C., 1963).

10. Green, L. H. and Smith, T. W.: The use of digitalis in patients with pulmonary disease. Ann. Intern. Med., 87: 459 (1977).

11. Hayes, S. L., Lasseter, K. C., Davolos, D. D., and Palmer, R. F.: Amrinone-a novel cardiac inotrope: effects after oral administrations in normal man. Clin. Res., 27: 542A (1979).

12. Keung, E., LeJemtel, P. H., Ribner, H. S., Wexler, J., and Sonnenblick, E. H.: Amrinone, a new oral inotropic agent in the treatment of heart failure. Clin. Res., 7: 502A (1979).

13. Klein, N. A., Siskind, S. J., Frishman, W. H., Sonnenblick, E. H., and LeJemtel, P. H.: Hemodynamic comparison of intravenous amrinone and dobutamine in patients with chronic congestive heart failure. Am. J. Cardiol., 48: 170 (1981).

14. LeJemtel, P. H., Keung, E., Sonnenblick, E. H., Ribner, H. S., Matsumoto, M., Davis, R., Schwartz, W., Alousi, A. A., and Davalos, D.: Amrinone-a new nonglycosidic, non-adrenergic cardiotonic agent effective in the treatment of intractable myocardial failure in man. Circulation, 59: 1098 (1979).

15. Lock, J. E.: Pharmacologic approaches to the treatment of pulmonary hypertension. In: G. J. Peckham and M. A. Heymann, (Eds.): Cardiovascular Sequelae of Asphyxia in the Newborn, Report of The Eighty-Third Ross Conference on Pediatric Research. pp. 94-99 (Ross Laboratories, Columbus, 1982).

16. Lock, J. E., Hamilton, F., Luide, H., Coceani, F., and Olley, P. M.: Direct pulmonary vascular responses in the conscious newborn lamb. J. Appl. Physiol.: Respir., Environ., Exer. Physiol., 48: 188 (1980).

17. Mecca, T. E. and Caldwell, R. W.: The pulmonary vasoconstricting action of digoxin: site of action on the sympathetic nervous system. Fed. Proc. (Abstract) 441: 1608 (1982).

18. Weber, K. T., Andrews, V., Janicki, J. S., Wilson, J. R., and Fishman, A. P. Amrinone and exercise performance in patients with chronic heart failure. Am. J. Cardiol., 48: 164 (1981).

19. Wynne, J., Malacoff, R. F., Bennoti, J. R., Curfman, T. D., Grossman, W. Holman, B. L., Smith, T. W., and Braunwld, E.: Oral amrinone in refractory congestive heart failure. Am. J. Cardiol., 45: 1245 (1980).

20. The authors would like to thank Teresa Niemi for technical and surgical assistance, Marietta Sattler for secretarial assistance, and Don Svendsen for photography.

21. Request for reprints should be addressed to: Dr. James E. Lock, Box 94 Mayo Memorial Building, University of Minnesota Hospitals, 420 Delaware Street S.E., Minneapolis, MN 55455.

22. This work was supported in part by Grant HL 28241 from the National Institutes of Health, and a grant from the American Heart Association, Minnesota Affiliate. Dr. Lock is an Established Investigator of the American Heart Association.

23. Received for publication August 3, 1982.

24. Accepted for publication February 4, 1983.

\title{
Oral Immunization to Milk Protein in Human Infants in the Presence of Passive Antibody
}

\author{
WOLFGANG MÜLLER, ${ }^{(28)}$ AXEL LIPPMANN, AND CHRISTIAN H. L. RIEGER \\ Department of Pediatrics, Medizinische Hochschule Hannover, Hannover, West Germany
}

\section{Summary}

The possible influence of maternal antibody on the immune response to bovine serum albumin (BSA), a normal cow's milk protein, was investigated in fullterm human neonates. Antibody production to BSA of 12 infants with passively acquired anti-BSA (Group I) was compared to the immune response of nine infants without passive anti-BSA at birth (Group II) during the first 6 months of life. All infants were raised on commercial cow's millk formulas containing BSA in concentrations from $0.4-4.0 \mathrm{mg} / \mathrm{dl}$. From 4 wk of age concentrations of circulating anti-BSA as measured by radioimmunoassay and enzyme-linked-immunosorbent-assay (ELISA) were higher in Group II, but differences were not statistically significant. There was no difference in the immune response between infants ingesting formulas with high BSA content compared to infants ingesting low concentrations of antigenic BSA. The main isotype associated with anti-BSA formation was IgG. IgA in measurable amounts appeared later and accounted for approximately $10 \%$ of circulating antibody in both groups at 6 months of age. Only small amounts of IgM- and IgE-anti-BSA were detected.

\section{Abbreviations}

ABC-33, antigen binding capacity-33

BSA, bovine serum albumin

BSA-N, bovine serum albumin-nitrogen

ELISA, enzyme-linked-immunosorbent assay

EU, ELISA units

GALT, gut-associated lymphoid tissue

OD, optical density
The placental transfer of specific antibodies to pathogenic organisms and to toxins protects the neonate effectively before he has formed active antibody. Studies in human infants and in animals suggest that this early immune response is mainly elicited by antigens derived from gut bacteria and from food $(1,7,21,26)$. For example, human neonates are able to form IgM and $\mathrm{IgG}$ antibody to BSA when born after 36 wk of gestation $(19,20)$. Similarly, formation of antibodies to gut bacteria, e.g., to Salmonella $\mathrm{O}$ and $\mathrm{H}$ antigens and to the capsular antigens of $E$. coli has been demonstrated $(22,23)$. Natural antibodies against intestinal bacteria are thought to provide protection against disease because they crossreact with a number of important pathogens (1-3, 16, 22, 23).

The conditions which govern the immune response to enteric antigens are incompletely understood. Similar to the response of human neonates, the feeding of BSA to adult rabbits regularly results in the formation of active anti-BSA, whereas newborn rabbits and adult rats develop immunologic unresponsiveness after oral application of protein antigens $(17,25)$.

One of the factors that may affect neonatal immune responses is the presence of passive antibody. Studies on the effect of such antibody in human infants have shown suppression or enhancement of antibody formation to parenteral application of diphtheria toxoid $(4,13)$, whereas the response to oral polio vaccine was not affected by either circulating or secretory antibody of the mother (10). No effect of passive antibody on the immune response to BSA was seen in adult rabbits (18).

Interactions between passive antibody and antigen may depend on the type of antigen, the amount of passive antibody present, the time and mode of immunization, and the study model. Application of results from animal studies to humans is difficult, among 